\title{
O Processo de Criação do Tradutor ${ }^{1}$
}

\author{
Sergio Romanelli ${ }^{2}$
}

\begin{abstract}
RESUMO
Pretende-se mostrar, nesta comunicação, em uma perspectiva interdisciplinar, como a Crítica Genética pode auxiliar a Teoria da Tradução, e vice-versa, através da análise dos manuscritos da tradutora e poeta italiana Virgillito. Para dar conta desse complexo objeto de estudo, utilizar-se-ão princípios da Crítica Genética e dos Estudos Descritivos da Tradução, harmonizados ao novo paradigma do pensamento sistêmico, buscando aproximar, analisar, descrever, conhecer e explicar esse objeto de estudo muito peculiar.
\end{abstract}

PALAVRAS-CHAVE: Crítica Genética; Estudos Descritivos da Tradução; Rina Sara Virgillito.

\section{ABSTRACT}

This essay shows how the methodology of Genetic Criticism can help Translation Studies and viceversa. It proposes an interdisciplinary approach. This argument is illustrated through the analysis of manuscripts produced by the Italian poet Virgillito. In dealing with this complex corpus, principles of Genetic Criticism and of Descriptive Translation Studies have been used in line with the new paradigm of the systemic approach. It aims to combine different fields of study, as well as to analyze, describe, gather more knowledge about and explain this subject

KEYWORDS: Genetic Criticism; Descriptive Translation Studies; Rina Sara Virgillito.

Pela primeira vez, de fato, tenta-se uma parceria teórica e metodológica entre a Crítica Genética e a Teoria da Tradução para se estudar o processo criativo do tradutor, a partir de seus manuscritos. Busca-se reconstituir de uma forma empírica, com base nos dados colhidos e no corpus delimitado, o processo criativo do tradutor, tendo em vista detectar as leis e as normas seguidas, bem como as razões, as influências de vários tipos que o teriam levado a determinadas escolhas dentro de seu procedimento tradutório. Parece relevante destacar a novidade da proposta desta pesquisa, que pretende aplicar a Crítica Genética ao estudo de manuscritos de traduções ${ }^{3}$. Pela primeira vez, também, faz-se isso

1 Este artigo é uma síntese da tese apresentada, com bolsa CAPES, ao curso de Doutorado em Letras e Linguística, Instituto de Letras, Universidade Federal da Bahia e intitulada A gênese de um processo tradutório: os manuscritos de Rina Sara Virgillito; sob orientação da Prof. Dr. Sílvia Maria Guerra Anastácio e defendida em 09 de junho de 2006.

${ }^{2}$ Professor do Departamento de Línguas e Literaturas estrangeiras do Centro de Comunicação e Expressão e na PGET (Pós-gradução em Estudos da Tradução) da Universidade Federal de Santa Catarina. sergioroma70@gmail.com

3 Após uma investigação bibliográfica, soube-se que somente uma pesquisadora, Cristiane Grando, trabalha, em São Paulo, com Crítica Genética e Tradução, não para reconstituir o processo criativo do tradutor, mas sim, mostrando como a tradução dos manuscritos poderia ajudar na interpretação do texto. Para um maior aprofundamento, consultar os seguintes artigos publicados: GRANDO, C. Leitura Genética do Poema "Se Tivesse Madeira e llusões" de Hilda Hist. Manuscrítica. Revista de Crítica Genética. São Paulo: APML, n. 7, 1998, p. 91110. GRANDO, C. Estrutura formal Dos Poemas de Amavisse: os Paralelismos Hilstianos. Manuscrítica. Revista de Crítica Genética. São Paulo: APML, n. 8, 1999, p. 73-87. GRANDO, C. Genética e tradução: a poética de Hilda 
com manuscritos em língua italiana, já que até agora, os principais grupos de pesquisas deste país trabalharam com dossiês de autores brasileiros ou de língua portuguesa, com autores de língua francesa e inglesa.

A Crítica Genética ${ }^{4}$ revela-se, com sua metodologia de reconstituição dos vestígios deixados pelo autor/tradutor ao longo do seu percurso criativo, uma aliada nova e eficaz nos estudos sobre tradução. A constatação básica em que ela se fundamenta, como sustenta Cecília Salles, é que:

[...] o texto definitivo de uma obra, publicado ou publicável, é, com raras exceções, resultado de um trabalho que se caracteriza por uma transformação progressiva. A obra surge a partir de um investimento de tempo, dedicação, e disciplina por parte do escritor [...] A obra entregue ao público é precedida por um complexo processo [...] (SALLES, 1992: p. 17).

O objetivo da Crítica Genética é mostrar o avesso do texto publicado, ou seja, aquele processo complexo e interminável de correções, pesquisas, planos, esboços, a que o público geral não tem acesso, e cujo desconhecimento leva à crença, ainda muito comum, da obra que nasce já pronta como resultado espontâneo de pura inspiração. Essa nova orientação metodológica concebe a obra de arte não como um mero produto considerado acabado pelo artista, mas como uma cadeia infinita de agregação de idéias. Valoriza-se, de fato, o processo, e este é privilegiado em relação ao produto considerado final. Acompanhando esse processo, a Crítica Genética se propõe a tirar a criação artística do âmbito do inexplicável no qual parecia estar. Pretende, dessa forma, abordar as obras de arte e observá-las a partir de seus percursos de fabricação para conhecer os seus mecanismos construtores. Ademais, esse processo passa a ser visto dentro de um contexto cultural específico, ao qual se integra e, o qual, de certo modo, reflete.

Se o manuscrito constitui o objeto físico principal do estudo da Crítica Genética, as leis, as recorrências e as normas desse processo, assim como acontece nos Estudos Descritivos da Tradução, ${ }^{5}$ constituem a preocupação da abordagem genética. Cada autor, de

Hist. Manuscrítica. Revista de Crítica Genética. São Paulo: APML, n. 10, 2001, p. 141- 153.

4 Esta metodologia de pesquisa nasceu na França, em 1968, quando por iniciativa de Louis Hay, formou-se um pequeno grupo, datando de 1965 a 1975, de pesquisadores encarregados de organizar os manuscritos do poeta alemão Heinrich Heine. Os problemas metodológicos que esses autores encontraram, ao lidar com os manuscritos, desencadearam um profundo interesse pelos estudos dos manuscritos, que acabaram envolvendo outros estudiosos e levando à criação de um laboratório, o ITEM, o que ocorreu da década de 70 até meado da década de 80. Nessa época os pesquisadores teriam se dedicado exclusivamente ao estudo do manuscrito literário. Finalmente, a Crítica Genética espalhou-se pelo mundo e foi introduzida no Brasil por Philippe Willemart, em 1985, começando-se a refletir sobre os princípios fundamentais, bem como sobre a legitimidade da disciplina, ao se abrir espaço para a transdisciplinaridade da Crítica Genética. Para outras informações ver referências bibliográficas.

5 Nos anos 80, os Estudos da Tradução focalizaram, de forma mais precisa, o aspecto prático dessa atividade, através de uma abordagem descritiva. A maioria dos debates concentrou-se sobre os métodos mais proveitosos para descrever a tradução literária e determinar comportamentos normativos no âmbito tradutório, detendo-se apenas, em uma segunda fase, ao aspecto teórico. Theo Hermans teve o mérito de coletar os estudos dos principais teóricos dessa fase no seu livro The Manipulation of Literature (1985). Um dos principais teóricos do grupo, José Lambert (1985), sugere que todos os aspectos funcionalmente relevantes da atividade tradutória $\sim 88 \sim$ 
fato, segue um próprio mecanismo de produção em que intervêm vários fatores endógenos e exógenos (ou polissistemas) ${ }^{6}$ de natureza diversa e que influenciam de forma significativa o seu desenvolvimento:

O geneticista [...] pretende tornar a gênese legível, [...] o texto (re)estabelecido em sua gênese, revela fases da escritura, mostra o autor em seu fazer literário, na medida em que reconstitui os paradigmas visitados durante a aventura da criação poética. (SALLES, 1992: p. 19).

Pelo suposto até o presente, pode-se observar que a Crítica Genética e os Estudos Descritivos possuem o mesmo paradigma, ou seja, uma metodologia similar e, sobretudo, princípios teóricos que funcionam em perfeita sintonia. Ambos se servem de uma metodologia de investigação de caráter indutivo. A primeira, ao estudar o manuscrito, visa chegar a:

[...] possíveis conclusões relativas a uma teoria da criação. Conclusões essas não mais baseadas em hipóteses desenvolvidas de forma dedutiva, a partir da obra acabada ou a partir de depoimentos de artistas. A crítica genética faz uso de inferências partindo de fatos concretos que funcionam como índices de suporte para uma teoria. Registra os dados de fato, da experiência viva, para corroborar dados teóricos, ou seja, é um processo de investigação experimental de suposições teóricas (SALLES, 1992: p. 33-4).

Da mesma forma, os Estudos Descritivos da Tradução não partem de pressupostos $a$ priori, mas de dados empíricos das traduções para remontar, através da análise dos textos editados, as leis e constrições sofridas pelo tradutor, ao longo de seu processo tradutório. Devido, então, à natureza dessas duas metodologias, pareceu lógico aproximá-las, pela primeira vez, aplicando-as ao estudo de manuscritos tradutórios. Segundo Serge Bourjea, a Crítica Genética:

[...] possibilita, de fato, duas coisas importantes no campo da Tradução: 1) ela pode constituir uma nova tarefa, (impossível), quanto à tradução dos manuscritos literários $[. .$.$] ; 2) a Genética deve permitir, através de um melhor conhecimento do$ processo da inventividade literária, um trabalho de leitura/ re-escritura mais fino ou mais adequado para o tradutor da poesia (O negrito é do autor) (1998: p. 48).

devem ser observados no seu contexto histórico. Dever-se-ão procurar, segundo Lambert, as regularidades nos fenômenos tradutórios em uma situação cultural real o que leva a uma evolução da teoria da tradução, bem como a uma redefinição de algumas concepções e do próprio conceito do que é um texto traduzido.

60 conceito de polissistema recebeu uma atenção considerável a partir dos anos 80 e ele se norteia nas obras dos últimos formalistas russos, como Jurij Tynjanov e Roman Jakobson. A contribuição principal dos formalistas foi ter desenvolvido essa noção de sistema. O termo começou a ser usado para denotar uma estrutura multifacetada de elementos que interagem um sobre o outro e, partindo dessa teorização dos formalistas, Even-Zohar desenvolveu a Teoria dos Polissistemas. 
Quais são, de fato, as etapas que levam um tradutor a escolher ou considerar como aceitável determinada versão de um texto? Quais as justificativas dessas escolhas e qual o material de referência que o tradutor usa? Essas são perguntas às quais a Crítica Genética pode responder com sua metodologia. Neste caso, também, o objeto de estudo da Crítica Genética é o caminho percorrido pelo tradutor para chegar à obra entregue ao público. Estuda-se o processo criativo a partir das marcas deixadas pelo tradutor. $O$ objeto de estudo do geneticista é um objeto móvel constituído por anotações, rascunhos, diários, fragmentos vários, que caracterizam um objeto em criação. A fundamentação principal desse paradigma de pesquisa é a concepção de que, para os críticos genéticos, tanto a obra publicada quanto o seu rascunho são um único objeto. A organização desse material tão heterogêneo é a primeira tarefa do geneticista. De modo que, uma vez estabelecido o dossiê genético ou prototexto $^{7}$ de um determinado autor, o pesquisador, ao fim de torná-lo legível, deve organizá-lo, empenhando-se na descrição e transcrição dos documentos ${ }^{8}$.

O objeto desta pesquisa ${ }^{9}$ poderia ser comparado a um prisma com três faces: um lado estaria ocupado por um manuscrito, o segundo por uma tradução e o terceiro por um processo de criação. Trata-se dos manuscritos de 114 poemas de Emily Dickinson traduzidos pela poeta e tradutora italiana Rina Sara Virgillito. Os cinco cadernos manuscritos foram encontrados em agosto de 1996, após a morte da poeta, na sua casa em Bergamo, na Itália, pela amiga e herdeira universal, Sonia Giorgi. A tradução dos poemas de Dickinson foi o último empreendimento literário da poeta, que, por causa da morte, ficara inacabado. Os

70 prototexto, segundo Bellemin-Noël, primeiro definidor, em 1972, desse termo, “[...] é uma certa reconstrução dos antecedentes de um texto, estabelecida pelo crítico com o auxílio de um método específico, destinada a ser objeto de uma leitura em continuidade com o dado definitivo. À delimitação empírica daquilo que, em um dado momento, se julgou ser o texto, acrescenta-se um recorte metodológico. (BELLEMIN-NOËL, 1993: p. 141).

8 Existem vários tipos de transcrições: nesta pesquisa foi adotada a linear, que consiste na reprodução datilográfica de um manuscrito, que transcreve todos os elementos do original, mas sem respeitar a topografia da página. Por não existir ainda um consenso acerca do código a ser utilizado, ou uma padronização, foram adotados os seguintes operadores:

\# $\quad$ versão / /? leitura duvidosa[/ /?] leitura duvidosa de parte ou palavra riscada/?/ palavra ou parte de palavra ilegível[/?/] palavra ou parte de palavra riscada ilegível< > acréscimo $\gg \quad$ acréscimo à direita $\quad$ acréscimo à esquerda * para comentários do pesquisador[ ] apagado( ) substituem o circulado do manuscrito. $\downarrow \quad$ substitui deslocamento para baixo. $\uparrow \quad$ substitui deslocamento para cima. $\rightarrow \quad$ substitui deslocamento para a direita. $\leftarrow \quad$ substitui deslocamento para a esquerda.

9 O prototexto desta pesquisa ou o dossiê genético constitui-se dos seguintes documentos: Os fac-símiles de cinco cadernos com traduções manuscritas de poemas de Emily Dickinson feitas por Rina Sara Virgillito e guardados junto ao Arquivo Histórico de Florença; O catálogo da Biblioteca Rina Sara Virgillito; Os fac-símiles de algumas folhas manuscritas da agenda particular da autora de 1996 cedida pela herdeira universal, Prof. a Giorgi; 11 folhas avulsas em fac-símile com traduções de poemas de Dickinson trazendo a data do dia 17/10/ 1995, guardadas pela Prof. a Dr. a Sonia Giorgi, em Bergamo, na Itália; Dois livros originais que pertenceram à autora: um de poesias e um de cartas de Emily Dickinson, editados pela editora Bompiani, em 1995, e organizados por Margherita Guidacci, contendo anotações manuscritas de Virgillito, cedidos pela Prof. a Giorgi; Fac-símiles das introduções e das notas biobibliográficas de cinco livros do Fundo Virgillito: todos são edições de poemas de Dickinson traduzidos para o italiano e que contêm anotações manuscritas de Virgillito: DICKINSON, Emily. Poesie. A cura di Guido Errante. Milano: Mondadori, 1964; DICKINSON, Emily. Le stanze d'alabastro. A cura di Nadia Campana. Milano: UEF, 1983; DICKINSON, Emily. Poesie. A cura di Massimo Bagicalupo. Milano: Oscar Mondadori, 1995; DICKINSON, Emily. Silenzi. A cura di Barbara Lanati. Milano: Feltrinelli, 1986; DICKINSON, Emily. Poesie, traduzidas por Margherita Guidacci, Milano: Rizzoli, 1979. 
cinco cadernos foram estudados durante cinco anos, período em que se realizaram também a análise filológica e a transcrição dos cadernos, em vista de uma possível publicação, o que finalmente ocorreu em 2002, em Milão, pela editora Garzanti.

A primeira etapa da análise do dossiê Virgillito conduzida consultando os livros de poemas de Dickinson - que a tradutora leu e fez anotações às margens dos versos, registrando as datas das sucessivas leituras - e o catálogo da biblioteca pessoal, destaca fases nítidas na gênese das traduções de Dickinson: observa-se, então, que em 1957, Virgillito lê e anota parcialmente a coletânea de poemas de Dickinson traduzidos por Errante e, também, traduz algumas palavras dos poemas; em 1979, lê e anota a coletânea organizada por Guidacci e traduz algumas estrofes dos poemas; em 1983, volta ao texto de Errante; em 1984, lê e anota o de Nadia Campana; em 1987, lê e anota o de Barbara Lanati; em setembro de 1995, lê o de Bagicalupo; em outubro de 1995, volta ao de Campana e ao de Lanati, anotando no livro as primeiras traduções integrais de poemas da autora americana; em dezembro de 1995, lê e anota o de Guidacci; e em janeiro de 1996, lê e anota a coletânea de cartas. Se, então, torna-se evidente que outubro de 1995 é uma data crucial para se estabelecer o começo sistemático do trabalho de tradução e redação de Virgillito. Pode-se afirmar, também, que os vestígios deixados nos livros de Errante e Guidacci e, mais freqüentemente, no de Lanati, constituem uma verdadeira fase pré-redacional explanatória ${ }^{10}$ dos poemas. Aqui, a tradutora, em um clímax de crescente interesse pela poética da autora americana, adquire mais autoconfiança e tenta algumas tímidas traduções, até chegar ao projeto sistemático da tradução de 114 poesias. De fato, o aumento das marcas deixadas nos manuscritos parece demonstrar que a autora, ao ler o texto, teria começado a traduzir, em um primeiro momento, palavras e frases esporádicas, para só mais adiante deter-se em estrofes e até poemas, como mostram as marcas deixadas nos livros de Campana e Lanati.

Numa segunda etapa da análise do prototexto, buscou-se entender qual a idéia de tradução de Virgillito ao se aproximar de texto de Dickinson. De fato, antes de ter uma idéia do autor a ser traduzido, o tradutor, ao lidar com uma obra, já demonstra conhecimentos sobre tradução, que são provenientes de suas leituras, de sua formação, ideologia, época histórica e experiência prévia. Pode-se, então, tentar remontar à idéia de tradução a partir de seus metatextos, dos depoimentos do próprio tradutor e, no caso de Virgillito, a partir dos livros de tradução lidos e possuídos pelo tradutor em sua biblioteca pessoal, além dos próprios manuscritos tradutórios.

Virgillito chegara ao texto dickinsoniano, após anos de experiência como tradutora e muitas obras traduzidas de vários idiomas antigos e modernos. As introduções e as notas escritas pela autora, por ocasião dessas publicações, assim como as resenhas e os depoimentos publicados sobre seu trabalho foram fundamentais para ajudar a reconstituir o seu percurso tradutório. Antes de qualquer coisa, porém, pode-se buscar, em sua biblioteca pessoal, textos que possam favorecer o esclarecimento desse percurso. No catálogo de sua biblioteca, encontra-se somente um livro sobre teoria da tradução, a saber, o de Roman Jakobson, Saggi di linguistica generale, organizado por Luigi Heilmann e publicado em Milão

10 Conforme foi teorizado por de Biasi (1997), existem quatro grandes fases genéticas em cada dossiê: a fase pré-redacional, a redacional, a pré-editorial e a editorial. A fase pré-redacional se compõe de duas sub-fases: uma fase explanatória e uma de decisão, sendo que a fase explanatória "[...] pode resultar em várias tentativas espaçadas no tempo, algumas muito anteriores à redação [...]” (BIASI, p. 10). Sempre segundo de Biasi, essa fase pré-redacional se traduziria, em seu aspecto explanatório, em "[...] uma sucessão esporádica de falsas partidas escalonadas no tempo antes que o projeto propriamente dito se destaque sob a forma de uma idéia de redação que poderá evoluir favoravelmente [...]" (1997, p. 11). 
pela editora Feltrinelli, em 1976. Evidentemente, apesar da presença desse livro não ser um indício suficiente para se poder inserir a tradutora dentro de um paradigma tradutório mais prescritivo, como era o que Jakobson representava, sugere-se que tal fato, por outro lado, não deixa de ter algum significado. Ainda mais se levarmos em conta que, em sua introdução crítica à tradução dos sonetos de Shakespeare, Virgillito, ao justificar os seus critérios tradutórios, cita exatamente um trecho da obra mencionada:

\begin{abstract}
Algumas palavras acerca dos critérios e das escolhas da presente versão. Pareceu necessário, para não trair, na medida do possível, a força da escansão originária, retomar a estrutura métrica do soneto elisabetano [...] "A poesia", escreve R. Jakobson, "é intraduzível por definição, sendo possível só uma transposição criativa". Tentou-se, então, este caminho [...] (Tradução nossa) (VIRGILLITO, 1988: p. 22). ${ }^{11}$
\end{abstract}

A suposição de que Virgillito não teria seguido um paradigma tradutório definido, mas que, ao contrário, houvesse adaptado o seu processo tradutório à natureza do texto a ser traduzido, ao próprio estilo poético, sendo também ela uma poeta, e ao seu público-alvo, se confirma na leitura das análises que os críticos fizeram de suas traduções publicadas das obras de Shakespeare, de Barret-Browning e, sobretudo, de Dickinson:

Ela que no seu traduzir tinha sempre almejado uma equilibrada elegância, parece, neste caso contagiada pelo dinamismo do texto dickinsoniano - elíptico, condensado, vibrante - e pronta para perseguir cada palavra, além da folha escrita, na margem, no branco, para devolvê-la intacta como uma pérola roubada das profundezas (Tradução nossa) (BULGHERONI, 2002: p. XXII). ${ }^{12}$

$\mathrm{Na}$ terceira etapa da pesquisa foram analisados de forma mais aprofundada os manuscritos que demonstraram uma complexa obra de elaboração, trazendo todos eles, na capa ou na folha de rosto, a data e a classificação das primeiras versões de cada tradução e suas transcrições feitas pela tradutora. $O$ primeiro caderno contém as primeiras versões dos poemas escolhidos e todas exibem: a data da primeira composição; o lugar (quase sempre compunha em cafés); a hora; a data e o lugar da segunda versão ou das sucessivas versões; o número da poesia, conforme numeração estabelecida pelo texto de Johnson, o organizador da primeira coletânea completa dos poemas de Dickinson; e, em alguns casos, também a numeração estabelecida pelos tradutores Campana e Errante. De fato, Virgillito marca em muitas poesias o nome do tradutor para indicar que está usando como referência a versão em inglês escolhida por aquele tradutor (Guidacci, Bagicalupo, Errante, Campana e Lanati), desde que existem várias versões dos poemas originais de Dickinson. Ela marca o número da poesia, primeiro porque cada um desses tradutores optou por diferentes variantes dos poemas em sua versão original inglesa; e segundo, porque como Virgillito não possuía a edição completa dos poemas de Dickinson organizada por Johnson, esses livros continham os

11 Qualche parola intorno ai criteri e le scelte della presente versione. È parsa necessità, per non tradire, quanto si poteva, la forza della scansione originaria, riprendere la struttura metrica del sonetto elisabettiano [...] 'La poesia', scrive R. Jakobson, 'è intraducibile per definizione. È possibile solo la trasposizione creativa'. Si è tentata dunque questa via [...].

12 Lei che nel suo tradurre aveva mirato a un'inquieta ma levigata compiutezza, sembra qui contagiata dall'enigmatico dinamismo del testo dickinsoniano - ellittico, compresso, vibrante - e pronta a inseguire ogni parola oltre la pagina scritta, nel margine, nel bianco, per restituirla intatta come una perla strappata al profondo. 
originais em língua inglesa, que se tornaram seus textos de referência. Não foi possível, através das marcas deixadas por Virgillito, entender com que critério escolhera, como referência para seu trabalho, um tradutor ao invés de outro.

A dinâmica de trabalho que os vestígios dos cadernos de Virgillito deixam entrever era a seguinte: ela escrevia, quase de um só jato, a primeira versão do poema que, às vezes, corrigia imediatamente para, em geral, transcrevê-la em um outro caderno a fim de relê-la e corrigi-la de novo. Não existem transcrições definitivas desses poemas, mas somente provisórias, como ela mesma marcou nas capas do primeiro e do segundo caderno de transcrições. Além disso, um dado interessante que emerge dessa análise é que, em muitos casos, encontram-se nas agendas junto às traduções, outros novos poemas. Esse dado haveria de confirmar um traço peculiar do trabalho intelectual e poético de Virgillito, que é a sua vocação para a poesia e para a tradução, confirmando a tese de que as duas atividades aconteceram em paralelo na vida da poeta italiana e, por isso, se influenciaram reciprocamente.

Há aspectos circunstanciais ou contingenciais que teriam reflexos importantes na criação da tradutora, caso se considere, por exemplo, que no caso das traduções de Dickinson, o fato de Virgillito compor fora de casa a obrigava a levar poucos livros consigo e nenhum dicionário. Por isso, também, a cada vez que compunha, escolhia somente uma das cinco coletâneas dos poemas de Dickinson - como texto de referência - com que trabalhava naquele determinado momento, sempre marcando as dúvidas que tinha sobre questões mais diversas, sobretudo de ordem linguística, e que, em seguida, haveria de procurar resolver. Em muitos casos, Virgillito não somente anotava e sublinhava opções de tradução duvidosas, mas, também, escrevia ao lado do termo em italiano, a palavra em inglês, como está exemplificado nos seguintes trechos:

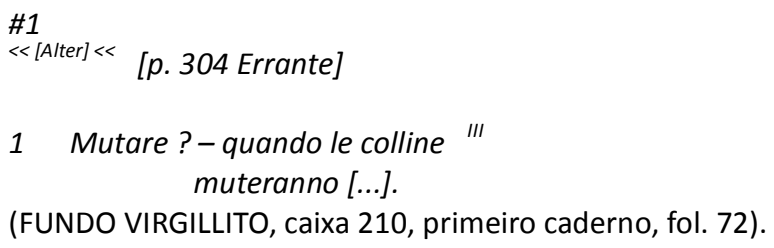

Nesse primeiro trecho, a dúvida é sobre o verbo Alter que, na versão referida, é traduzido por Mutare (Mudar); na segunda versão, contida no terceiro caderno, o problema ainda não estaria resolvido, já que Virgillito traduz, em um primeiro momento por Mutare, para depois corrigir para Mutarmi (Mudar-me):

\#2

[304 Errante]*

$$
>\frac{\text { Rivedere }}{>18>>}
$$

1 Mutar $[e]<m i$ ? $>$ quando le colline

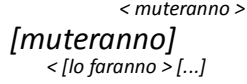

(FUNDO VIRGILLITO, caixa 210, terceiro caderno, fol. 23).

Mas o Rivedere (Rever) marcado em caneta vermelha, acima do primeiro verso, indica 
que a dúvida não teve uma solução satisfatória e permaneceu em aberto. Já em um outro poema, no fólio 56 do segundo caderno, a dúvida diz respeito ainda à tradução do verbo to pile:

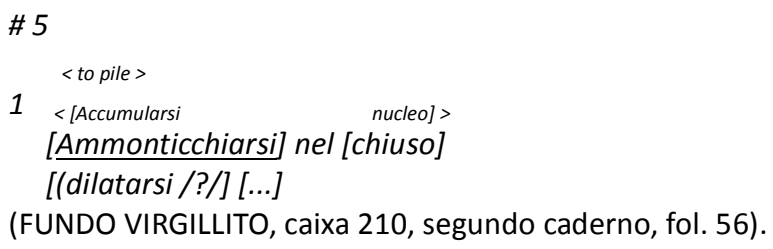

Esta tem sido, talvez, a mais trabalhada por Virgillito, desde que há nove diferentes versões em que o problema principal que parece ter preocupado a tradutora gira em torno de como traduzir o verbo to pile. Nesta versão, Virgillito opta, em um primeiro momento, pelo termo Ammonticchiarsi (Apinhar-se) para descartá-lo, e adotar o verbo dilatarsi (dilatarse), também em seguida descartado e substituído por comprimersi (comprimir-se); mais uma vez, é ainda alterado na correção e, também, na transcrição, como atestam as notas em vermelho. Adota-se, então, o verbo Accumularsi (Acumular-se) para, finalmente, ser reaproveitada uma opção anterior, o verbo comprimersi (comprimir-se). Nas outras oito versões do mesmo poema a questão continua em aberto, recorrendo-se a eliminações, substituições e reconsiderações dos mesmos verbos, anteriormente descartados, até chegar, após três meses, na nona versão, à confirmação de uma opção, muitas vezes, tentada, comprimersi:

\#1

1247 [[Concentrarsi] come tuono al [suo] nucleo [...].

(FUNDO VIRGILLITO, caixa 210, primeiro caderno, fol. 39).

\#2

1 Come tuono restringersi nel nucleo

Restringersi come tuono al nucleo addensarsi concentrarsi [...].

(FUNDO VIRGILLITO, caixa 210, primeiro caderno, fol. 40).

\#3

$\underline{R \text { Riv }} 1247$

ore $18: 30$

1 [Addensarsi come tuono al nucleo [...].

(FUNDO VIRGILLITO, caixa 210, primeiro caderno, fol. 41).

\#4

$1<$ controll. > $1247-27 / 10$ <addensarsi [sul limite?] >
< concentrarsial nucleo >

Come tuono restringersi nel nucleo [...]. (FUNDO VIRGILLITO, caixa 210, primeiro caderno, fol. 45).

\#6

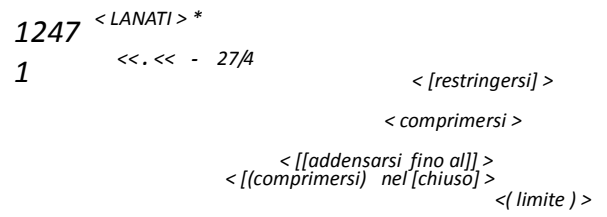

5 Come tuono [concentrarsi al nucleo -] [...]. (FUNDO VIRGILLITO, caixa 210, terceiro caderno, fol. 8).

\#7

1247

1

$$
\begin{gathered}
<\text { (comprimersi })>\langle[\text { [nucleo }]]> \\
<[\text { comprimersi }]><\text { limite }> \\
<[\text { costringersi] nel }[(\text { chiuso })]>
\end{gathered}
$$

Come tuono [restringersi nel nucleo] [...]. 
(FUNDO VIRGILLITO, caixa 210, terceiro caderno, fol. 18).

\#8

(1247) <12.1.96>

1 $<$ limite >

Come tuono comprimersi nel [chiuso] [...]. (FUNDO VIRGILLITO, caixa 210, quarto caderno, fol.
10).

\#9

(1247) > . >

1 Come tuono comprimersi nel limite - [...].

(FUNDO VIRGILLITO, caixa 210, quarto caderno, fol. $32)$.

As marcas na folha mostram, portanto, um processo de aproximações e tentativas muitas vezes não resolvido, visto que a opção freqüentemente ficava em aberto, gerando possíveis versões, todas, a princípio, válidas, mas nenhuma considerada como definitiva. Assim é que tais exemplos confirmariam a suposição de que Virgillito trabalhava, sobretudo, em um primeiro momento, de forma instintiva, traduzindo de um só jato a primeira versão do poema escolhido; só para ainda trabalhá-lo e retrabalhá-lo, costumando ser as primeiras tentativas as mais criativas, e as sucessivas, as mais próximas do texto de partida. Percebe-se, ainda, que Virgillito, não obstante revelasse uma poética própria, durante o trabalho de tradução dos poemas de Dickinson, ela costumava descartar as escolhas mais originais e de efeito mais surpreendente.

Por meio da Crítica Genética, podem-se comparar as variantes contidas nos manuscritos de Virgillito, não somente acompanhando e entendendo o processo de tradução, mas, sobretudo, analisando a invenção artística de Virgillito. Nos casos de poemas com mais de três variantes, a atitude da tradutora parecia ser a de seguir, inicialmente, uma tradução bastante instintiva, que ia sendo refinada mediante aproximações lexicais e morfológicas; estas eram influenciadas por fatores contingenciais (como mencionado, não levava dicionário para traduzir), bem como pelo padrão do inglês, a língua de partida, e pelo seu próprio estilo poético. Portanto, à primeira vista, ao se analisar os cadernos dos manuscritos, esse trabalho poderia soar como uma criação artística marcada pela instabilidade, mas que acaba revelando, no decorrer da análise, uma sistematicidade em que as leis daquela criação emergem. Esse método sistemático de trabalho não diz respeito somente às traduções de Dickinson, mas também às outras que Virgillito fazia, como as de Shakespeare, Rilke e Barret Browning, bem como de seus próprios poemas, como se pode constatar ao consultar o Fundo Virgillito. Após uma primeira análise, observam-se várias recorrências similares entre as primeiras versões das traduções dos sonetos de Shakespeare e as encontradas nos manuscritos das traduções dos poemas de Dickinson. Ora, as recorrências encontradas nos cadernos dos poemas traduzidos de Dickinson constituem o ápice de uma verdadeira poética da criação, que abrange toda a obra de Virgillito, tanto a sua própria, quanto a tradutória. Além disso, revelam como Virgillito era uma leitora atenta, tanto da sua obra, quanto dos textos de outros escritores. De fato, a leitura e a releitura dos próprios textos, bem como as reflexões sobre a gênese da obra de arte, parecem ter sido a seiva vital com que Virgillito alimentava, continuamente, a sua criação. Este pode ser considerado como um verdadeiro sistema retroativo de input e de output, que não somente procedia dos polissistemas literários externos, mas, sobretudo, do próprio sistema criativo da autora, incluindo não somente as suas obras editadas, como as inéditas. Dessa forma, Virgillito procurava entender as leis de sua criação, sempre relendo e revisando todo o seu material, incessantemente, até os últimos dias de vida.

O método sistemático de trabalho e de criação da poeta italiana exemplifica e confirma a tese, segundo a qual, para um escritor/tradutor, a sua obra nunca está fechada e acabada, mas continua sendo, ainda depois de publicada, insatisfatória e provisória. A 
análise dos manuscritos realizada por Virgillito, assim como aquela feita pelo geneticista em uma fase posterior, aponta para o paradoxo inerente à criação: por um lado, vê-se como o trabalho meticuloso de revisão, transcrição, releitura e correção dos manuscritos parece indiciar a insatisfação, por parte do autor/leitor/tradutor, com a sua obra; por outro lado, entende-se como esse mesmo trabalho é nada mais que um processo instável e não previsível sobre o qual o autor não exerce tanto controle. Observa-se, inclusive, que em algumas fases da redação, o escritor é dominado e guiado pela força das palavras, seguindo um rumo inédito testemunhado pelas rasuras, pelos pontos de bifurcação e pelas reconsiderações, que aparecem no texto manuscrito. A análise desses manuscritos mostra, realmente, como a escrita parece ser um verdadeiro sistema complexo e instável, em que as leis da dispersão e da reorganização convivem em constante flutuação.

\section{REFERÊNCIAS BIBLIOGRÁFICAS}

BELLEMIN-NOËL, J. Reproduzir o manuscrito, apresentar os rascunhos, estabelecer um prototexto. Manuscrítica. Revista de Crítica Genética. São Paulo: APML, n. 4, 1993, p.127161.

BOURJEA, S. Valéry, tradução, gênese. In: Costa Luiz Angélico da (Org.). Limites da traduzibilidade. Salvador: Edufba, 1998, p. 47-55.

BULGHERONI, M. In lotta con l'angelo. In: DICKINSON, E. Poesie. Tradotte da Rina Sara Virgillito. Milano: Garzanti, 2002, p. XXII-XXIV.

FUNDO VIRGILLITO. Archivio di Stato di Firenze.

HERMANS, T. The Manipulation of Literature. Studies in Literary Translation. London \& Sidney: CROOM HELM, 1985.

LAMBERT, J.; GORP, H. von. On describing Translations. In: HERMANS T. (Ed.). The Manipulation of Literature. Studies in Literary Translation. London \& Sidney: Croom Helm, 1985, p. 42-53.

SALLES, C. Almeida. Crítica Genética. São Paulo: Educ, 1992.

VIRGILLITO, R. S. Introduzione. In: SHAKESPEARE, W. I Sonetti. Traduzione di Rina Sara Virgillito. Roma: G. T. E. Newton, 1988, p. 7-22.

Artigo recebido em: 02/06/09

Artigo aprovado em: 03/09/09

Referência eletrônica: ROMANELLI, Sergio. "O Processo de Criação do Tradutor", Revista Criação \& Crítica (online), n. 3, p.87-96, 2009. 